\title{
Detection and absolute quantification of betasatellites associated with okra yellow vein mosaic disease by $q P C R$
}

Article

Accepted Version

Creative Commons: Attribution-Noncommercial-No Derivative Works 4.0

Christy Jeyaseelan, T., Christy Jeyaseelan, E., De Costa, D. M. and Shaw, M. W. (2020) Detection and absolute quantification of betasatellites associated with okra yellow vein mosaic disease by qPCR. Journal of Virological Methods, 276. 113789. ISSN 0166-0934 doi:

https://doi.org/10.1016/j.jviromet.2019.113789 Available at https://centaur.reading.ac.uk/87791/

It is advisable to refer to the publisher's version if you intend to cite from the work. See Guidance on citing.

To link to this article DOI: http://dx.doi.org/10.1016/j.jviromet.2019.113789

Publisher: Elsevier

All outputs in CentAUR are protected by Intellectual Property Rights law, including copyright law. Copyright and IPR is retained by the creators or other copyright holders. Terms and conditions for use of this material are defined in the End User Agreement. 


\section{CentAUR}

Central Archive at the University of Reading

Reading's research outputs online 
Title: Detection and absolute quantification of betasatellites associated with okra yellow vein mosaic disease by qPCR

\section{Author names and affiliations:}

Tharmila Christy Jeyaseelan ${ }^{a, d}$, Emmanuel Christy Jeyaseelan ${ }^{a}$, Devika M. De Costa ${ }^{\text {b,d }}$, Michael Warren Shaw ${ }^{\mathrm{c}}$

a Department of Botany, Faculty of Science, University of Jaffna, Jaffna, JA 40000, Sri Lanka.

b Department of Agricultural Biology, Faculty of Agriculture, University of Peradeniya, Peradeniya, KY 20400, Sri Lanka.

${ }^{c}$ School of Agriculture, Policy and Development, University of Reading, Reading, RG6 6BZ, United Kingdom.

${ }^{d}$ Plant Protection Board of Study, Postgraduate Institute of Agriculture, University of Peradeniya, Peradeniya, KY 20400, Sri Lanka.

Corresponding author: Tharmila Christy Jeyaseelan

E-mail address: siva.tharmi3@gmail.com / cjtharmila@univ.jfn.ac.lk 


\section{Abstract}

Okra yellow vein mosaic disease (OYVMD) causes serious loss in okra production in Sri Lanka. Therefore, screening of resistant okra verities is an essential need to control the disease. As the available qualitative and semi-quantitative methods failed to detect latent infection the present study aimed to develop a quantitative PCR (qPCR) assay to detect and quantify one of the OYVMD causing agent, symptom modulating satellite molecules. A pair of primers targeting a portion of $\beta C 1$ gene of BYVMBs was designed and used to quantify of BYVMBs by absolute quantification method using SYBR Green I chemistry. Standard curves were prepared using series of dilutions of known copy number plasmids carrying target sequence. The mean amplification efficiency was $95 \%$ and the coefficient of determination was 0.994. The method was tested to find out the relation between symptoms and betasatellite titre in range of severity of OYVMD symptoms; the betasatellite titre increased with increasing severity. Interestingly, the method was able to detect BYVMBs present in apparently healthy plants growing in an infected field at a concentration which was not able to detect in end point PCR. Betasatellite titre was also measured in different ages of leaves and different positions. On average, the betasatellite titre in younger leaves was higher than in mature leaves and there were no significant variations in betasatellite titre in different position in each leaf. The assay was also tested as a tool to screen for resistant okra varieties; among the eight varieties tested no BYVMBs were detected in variety Maha F1. Varieties TV8 and MI5 had significantly higher copy number than rest of the varieties. The qPCR protocol described in this study is a useful method to detect and quantify BYVMBs in okra, especially for plant samples with betasatellite titre lower than the detection limit of conventional methods. 
Keywords: Betasatellites, qPCR, Okra, Yellow vein mosaic disease

Funding: This work was partially supported by the University Grant Commission, Sri Lanka [grant number UGC/DRIC/PG/2015(ii)/JFN/01]. 


\section{Detection and absolute quantification of betasatellites associated with okra yellow vein mosaic disease by qPCR}

\section{Introduction}

Okra yellow vein mosaic disease (OYVMD) causes serious yield losses in okra (Abelmoschus esculentus) cultivation, and it has become the most important disease in many countries in South Asia and Africa (Ndunguru and Rajabu 2004; Senevirathna et al., 2016; Asare-bediako et al., 2017; Jeyaseelan et al., 2018). OYVMD is caused by a monopartite begomovirus (family Geminiviridae) with a circular single stranded DNA genomic components of approximately $2.7 \mathrm{~kb}$, named DNA-A, which is encapsidated in geminate particles (Brown et al., 2015). According to recent $10^{\text {th }}$ ICTV report the following begomovirus species has been associated with okra; the species Bhendi yellow vein Bhubhaneswar virus, Bhendi yellow vein mosaic virus, Bhendi yellow vein mosaic Delhi virus, Bhendi yellow vein Haryana virus, Okra leaf curl Oman virus, Okra enation leaf curl virus, Okra mottle virus, Okra yellow crinckle virus and Okra yellow mosaic Mexico virus. However, there are several begomovirus species associated with okra are in unassigned category, for example, Bhendi yellow vein India virus, Bhendi yellow vein mosaic Maharashtra virus, Okra leaf curl Bihar virus, Okra leaf curl India virus, Okra leaf curl virus, Okra yellow vein mosaic virus etc., and in several research articles authors consider them as separate species. The monopartite begomovirus species are usually associated with a betasatellite species, for example, in Sri Lanka two different strains of Bhendi yellow vein mosaic betasatellite have been identified as associated with OYVMD (Jeyaseelan et al., 2018). The betasatellites have a single stranded DNA genome and have a gene coding for a protein known as $\beta \mathrm{C} 1$, which is essential for the development of typical symptoms in infected okra plants (Jose and Usha, 2003), suppressing post-transcriptional gene silencing and up-regulating viral DNA levels in planta (Briddon et al., 2008). 
Leaves of infected plants are characterized by alternate green and yellow patches, vein clearing and vein chlorosis, and a conspicuous yellow network of vein. In severe cases the chlorosis may extend to the inter-veinal area and may result in complete yellowing of leaves with stunting of plants (Senevirathna et al., 2016). Recently, it has been demonstrated that the characteristic yellow vein and mosaic symptoms arise on radish plant because the geminivirus betasatellite protein damages the structural and functional integrity of chloroplasts due to radish leaf curl disease infection (Bhattacharyya et al., 2015).

In Sri Lanka, cultivated okra varieties such as TV8 (locally known as 'Paal Vendi'), MI5 and MI7 show great susceptibility to OYVMD both in dry and wet zones. Because of this many farmers do not now select these varieties for cultivation. The variety TV8, formally popular and with a great market value in Northern Sri Lanka, has almost vanished because of its high susceptibility to OYVMD. The variety 'Haritha' was recommended as resistant to OYVMD by the Department of Agriculture, Sri Lanka, but in recent seasons the variety has suffered from high disease incidence, especially in dry zones of Sri Lanka (Senevirathna et al., 2016; Jeyaseelan et al., 2018). Strong sources of resistance have therefore yet to be identified in okra, although some varieties are tolerant to the disease, as some infected plants develop symptoms late in the seasons. Even though some new hybrids have been introduced by local seed companies, further studies are needed to confirm their resistance against OYVMD and other okra diseases. In addition, the introduced varieties are not favoured by consumers in Northern Sri Lanka. There is an urgent need to breed resistant varieties with highly marketable qualities and find resistant genetic material from which to breed.

Efforts to identify and exploit sources of resistance to OYVMD have already started in several countries, with screening based on visual symptoms and serological assays (Sergius and Esther, 2014; Asare-bediako et al., 2017; Kumar and Reddy, 2015; Kumar and Raju, 2017). This potentially misses latently infected plants which could hold reservoirs of 
inoculum in the field. An important tool in evaluating sources of resistance is therefore a method to determine the concentration of disease causing agents in infected plants.

Quantitative PCR (qPCR) has been used to detect and measure nucleic acids of a wide range of plant viruses with RNA or DNA genomes (Ammara et al., 2017; Bester et al., 2014; Rao and Sun, 2015; Shafiq et al., 2017). Recently a betasatellite has been reported as a key regulator of symptom induction. Therefore, in this study we present an absolute quantification method for Bhendi yellow vein mosaic betasatellite in okra which was achieved by developing a standard template from the $\beta C 1$ protein region of published Bhendi yellow vein mosaic betasatellite (BYVMB) genome sequences and subsequently producing standard curves based on this standard template using SYBR Green based protocol.

\section{Materials and methods}

\section{Developing a real time PCR protocol}

\section{Designing primers}

Sequences of BYVMBs were downloaded from the GenBank (Table 1). The retrieved sequences were aligned using ClustalW and areas of conservation were identified, to which four pairs of primers were designed and synthesized. Specificity of the primers was tested by endpoint PCR and qPCR with melt curve analysis. Only the primer pair qbetaF3 and qbetaR3 produced single peak in melt curve analysis. Therefore, in the final method only primer pair qbetaF3 (5' GGT TCG TTT ACA TCC ATT CCC A) and qbetaR3 (5', ACT GGG GTT CAA AAG CAG AAG) was used; all other primers were rejected. Specificity was further tested by PCR and qPCR assays with okra leaf samples showing OYVMD symptoms collected from five different places (Jaffna, Vavuniya, Trincomalee, Kandy and Matara), each located about $150 \mathrm{~km}$ apart. DNA samples of plants showing chilli leaf curl symptoms, tomato leaf curl 
symptoms, Ageratum conyzoides veinal chlorosis symptoms, cotton leaf curl symptoms, cassava mosaic symptoms, papaya mosaic symptoms and cucurbit mosaic symptoms were used as negative control.

\section{Conventional PCR, cloning and sequencing}

The DNA sample was extracted from symptomatic leaf samples (variety TV8) collected from Jaffna district, Sri Lanka. Conventional PCR was carried out with $20 \mu$ l reaction mix contained $10 \mu \mathrm{l}$ ready-made PCR mix (PCR Biosystems, UK), $1 \mu 1$ of qbetaF3 and qbetaR3 primers $(10 \mu \mathrm{M})$ and $1 \mu \mathrm{l}$ DNA sample. PCR cyclic conditions were $95^{\circ} \mathrm{C}$ for 1 min initial denaturation, then 35 cycles of denaturation at $95{ }^{\circ} \mathrm{C}$ for $15 \mathrm{~s}$, annealing at $58{ }^{\circ} \mathrm{C}$ for $15 \mathrm{~s}$ and extension at $72{ }^{\circ} \mathrm{C}$ for $30 \mathrm{~s}$, with final elongation at $72{ }^{\circ} \mathrm{C}$ for $5 \mathrm{~min}$. All the PCR reactions were done in a Veriti ${ }^{\circledR} 96$ well Thermal cycler (Applied Biosystems, USA). Size of the PCR product was confirmed by carrying out gel-electrophoresis on $2 \%$ agarose gel. The PCR product was purified using a spin column purification kit (NBS biological Ltd, Huntingdon, UK) and cloned into TOPO cloning vector using Zero Blunt TOPO PCR Cloning Kit (Life technologies, USA) as described in the manufacturer's guidelines. Transformed bacterial colonies were isolated on LB plates incorporating kanamycin. Colonies were picked and cultured in LB broth supplemented with kanamycin at $37{ }^{\circ} \mathrm{C}$ for $14-16 \mathrm{hr}$ in a shaking incubator at $250 \mathrm{rpm}$. Plasmid DNA was purified from bacteria using Gene JET plasmid purification kit (Thermo Scientific, USA). The resulting product was confirmed by commercial sequencing of the transformed plasmid DNA using M13 forward and reverse primers (Source Bioscience, UK).

\section{Standard curve preparation and quantification by qPCR assay}


Real time detection and quantification of BYVMB molecules associated with diseased samples was done using an absolute standard curve constructed from the cloned plasmids. The copy number of cloned plasmid was determined using a web tool 'DNA Copy Number and Dilution Calculator' provided by ThermoFisher Scientific (https://www.thermofisher.com). Initial copy number of cloned plasmids was adjusted to $10^{7}$ copies $/ \mu 1$; this solution was serially tenfold diluted down to $10^{2}$ copies/ $\mu 1$ (Shirima et al., 2017). Concentration of all the test samples was adjusted to $1 \mathrm{ng} / \mu \mathrm{l}$. Reactions for the test samples and samples with known copy number were carried out in same reaction plate. Test samples were quantified with three biological replicates (samples from three different plants). No template control (NTC) reactions were carried out with nano-pure water instead of DNA samples. Each reaction was carried out in $20 \mu \mathrm{l}$ reaction volume; $10 \mu \mathrm{l}$ SYBR Green mix (PCR Biosystems, UK) $1.6 \mu \mathrm{l}(0.8 \mu \mathrm{M})$ of betasatellite specific primer and $1 \mu 1$ of template DNA sample. Each qPCR reaction was carried out in duplicates under conditions optimized for the selected primers $\left(95^{\circ} \mathrm{C}\right.$ for 2 min and 40 cycles of $95{ }^{\circ} \mathrm{C}$ for $15 \mathrm{~s}, 60{ }^{\circ} \mathrm{C}$ for $\left.30 \mathrm{~s}\right)$ using a Step One Plus Real Time PCR system (Applied Biosystems, USA). At the end of the reaction a melting curve analysis was performed from 60 to $95{ }^{\circ} \mathrm{C}$, with an increment of 0.5 ${ }^{\circ} \mathrm{C}$ at $10 \mathrm{~s}$ intervals.

\section{Quantification of BYVMBs in tissues with specified severity of symptoms}

Okra leaf samples (variety TV8) were collected from three different cultivation fields in Jaffna, Sri Lanka (Fig. 1) so as to obtain samples with each of the following severities, on a 0-4 scale.

0 - No visible symptoms

1 - Vein clearing in youngest leaf only

2 - Leaf veins completely yellow but interveinal regions remain green 
3 - Whole leaf yellow coloured

4 - Yellowish and deformed pods with whole leaf yellow coloured. All leaves of the plant affected

Non-symptomatic, presumptively uninfected, leaf samples were collected from plants grown in insect proof cages.

Leaf samples were separately ground in liquid nitrogen using mortar and pestle. $20 \mathrm{mg}$ aliquots of the powder were taken in $1.5 \mathrm{ml}$ Eppendorf tubes separately and used for the DNA extraction. The DNA was extracted by using a method developed by Ghosh et al. (2009) with some modifications; the additional phenol-chloroform extraction step was omitted from the protocol.

The presence of begomovirus and betasatellites in the test samples was confirmed by endpoint PCR of both components. Partial genome of begomovirus DNA-A was amplified using a pair of degenerate primers (Deng et al., 1994) and full length of the betasatellite DNA was amplified with a pair of universal primers $\beta 01$ and $\beta 02$ as described by Briddon et al., (2002), using readymade PCR master mix (PCR Biosystems, UK). BYVMB copy number was also quantified as described in the previous section.

\section{Quantification of BYVMBs in different leaf position of infected okra}

Four okra plants with OYVMD symptoms (variety TV8, 6 week old) growing in pots were selected. Young $\left(2^{\text {nd }}\right.$ youngest leaf $)$ and mature $\left(10^{\text {th }}\right.$ youngest leaf $)$ leaf samples were collected, and the DNA was extracted from three different positions in each leaf (leaf lamina, petiole and midrib). Copy number of BYVMB was quantified in each sample using the qPCR assay described above.

\section{Screening of resistant okra varieties}


Leaf samples were collected from eight different varieties of okra (TV8, MI5, MI7, No.521, Maha F1, EU01, OKH1 and Haritha) grown in field conditions at the Agriculture research station, Tirunelveli, Jaffna. First sampling was done 8 weeks after sowing. The second youngest leaf was sampled from five plants out of 10 randomly selected symptomatic plants of each variety. In the remaining five plants the leaf was tagged and it was sampled two week later. For the control experiment, leaf samples were collected from okra plants which grew inside the insect proof cage. DNA was extracted from each sample and the copy number of BYVMB was quantified using the qPCR assay.

\section{Data analysis}

Absolute quantification of BYVMB was determined by running the default settings of the StepOne ${ }^{\mathrm{TM}}$ Real-Time PCR Software Version 2.3 (Life technologies, USA) on the StepOne Plus ${ }^{\mathrm{TM}}$ Real-Time PCR systems (Applied Biosystems USA). The variance between technical replicates was approximately two orders of magnitude less than between biological replicates in all experiments. Significance test and confidence limits were based on the variance between biological replicates. In the severity-titre and variety datasets, the variance between biological replicates (that is, replicate plants) increased in proportion to the mean for the category, so analysis was conducted on $\log _{10}$ transformed data, and means and $95 \%$ confidence limits were calculated by back transformation. The leaf age-tissue dataset was analysed untransformed, because the residual distribution was closer to normal on this scale than on the transformed scale. Analysis was done using Genstat v18 (VSNI) 


\section{Results}

\section{Confirmation of virus in the samples and primer specificity}

All the symptomatic okra leaf samples used in this study showed the presence of begomovirus DNA-A and betasatellite DNA following endpoint PCR with 20 ng total DNA. The intensity of bands increased with increasing severity (Fig. 2 and Fig. 3). The nonsymptomatic okra leaf sample used for severity scale 0 and leaf samples collected from plants grown in insect-proof cages did not show detectable bands in end-point PCR.

The pair of primers, qbetaF3 and qbetaR3 specifically amplified DNA sequences in leaf samples of OYVMD in both end-point PCR and qPCR, and failed to amplify DNA samples of chilli with leaf curl symptoms, tomato with leaf curl symptoms, A. conyzoides with veinal chlorosis symptoms, cotton with leaf curl symptoms, cassava with mosaic symptoms, papaya with mosaic symptoms and cucurbit with mosaic symptoms (Data not shown). The primer pair amplified a 106 bp length region of $\beta C 1$ gene of BYVMB in all symptomatic okra leaf samples tested, including samples collected from widely separated regions in Sri Lanka.

\section{Cloning, transformation and DNA sequencing}

Transformed bacteria were selected by blue-white screening on LB medium incorporated with X-gal and kanamycin $(50 \mu \mathrm{g} / \mathrm{ml})$. Colony PCR using betasatellite specific primers confirmed presence of the insert (data not shown). The cloned plasmids were sequenced (Source Bioscience, UK) to confirm the inserted $\beta C 1$ gene fragment (Fig. 4). The fragment showed $100 \%$ sequence identity with BYVMBs previously reported from Sri Lanka (KX174319, KX174318, KX174322). 


\section{Standard curves and qPCR amplification efficiency}

A standard curve was generated with series of dilutions $\left(10^{7}-10^{2}\right)$ of cloned plasmid DNA copy number. The PCR amplification mean efficiency of four replicates was $95.12 \pm 0.76 \%$ and the coefficient of determination $\left(\mathrm{R}^{2}\right)$ was $0.994 \pm 0.002$ (Fig. 5 a). When the copy number was diluted below $10^{3}$ copies amplification was still detected, but the efficiency of the reaction was lowered to $81 \%$ with $\mathrm{R}^{2}$ remaining high at 0.998 . Melting curve analysis of the PCR products showed a single peak at $76.6^{\circ} \mathrm{C}$ (Fig. $5 \mathrm{~b}$ ).

\section{Relation between symptoms and betasatellite titre}

The betasatellite titre was quantified and compared among various samples. The severity of symptoms produced in OYVMD varied among plants, ranging from mild initial vein clearing to complete yellowing of leaves. The qPCR assay was employed to explore the relationship between betasatellite titre and the symptom severity scale. The qPCR assay detected betasatellite in all samples including apparently healthy plants growing in an infected field. No amplification was detected in samples collected from insect proof cages but the symptomless field samples all had detectable BYVMB, with a mean copy number of 1216 . The betasatellite titre increased with increasing severity from severity scale 0 to scale 4 (Fig. 6); on the log scale there was a linear increase in copy number from scale point 1 to 4 (linear contrast $\mathrm{P}<0.001 \%$ ), accounting for about $99 \%$ of the differences between scale points). This corresponds to a proportionate increase in copy number from scale 1 to 4 of about $2.48 x$ per scale point. A comparison was also carried out between the end-point PCR with universal primers designed by Briddon et al. (2002) and qPCR assay developed in this study. The endpoint PCR failed to detect BYVMB in 20 ng samples of plants with severity scale 0 and 1 , but qPCR was able to detect betasatellite even in $1 \mathrm{ng}$ of these samples. 
Betasatellite titre was also measured in different ages of leaves, comparing the $2^{\text {nd }}$ youngest leaf and $10^{\text {th }}$ youngest leaf of symptomatic plants. In each leaf, DNA was extracted separately from lamina, petiole and midrib. On average, the betasatellite titre in younger leaves was higher than in mature leaves $\left(\mathrm{P}<0.001\right.$; mean copy number of BYVMB $1.05 \times 10^{6}$ and $3.64 \times 10^{5}$ in young and mature leaves respectively). On average, there were no significant variations in betasatellite titre between different positions in each leaf $(\mathrm{P}=0.2)$, but there was a marginally significant difference in the distribution of betasatellite in young and old leaves $(\mathrm{P}=0.04)$ (Fig. 7).

The qPCR assay was also tested as a tool to screen for resistant okra varieties. Eight varieties were tested. No BYVMBs were detected in variety Maha F1. In the remainder, virus titre significantly increased $(\mathrm{P}=0.05)$ with time. However, there was very weak correlation between the titres in weeks 8 and $10(\mathrm{r}=0.38 ; \mathrm{P}=0.2$; Fig. 8). In 8 week old plants the virus titre was significantly higher in varieties TV8, MI5 and MI7 than EU01, Haritha, OKH1 and No.521. Two weeks later, there had been a seven fold increase in copy number in cv. TV8. The variety EU01 had a relatively low copy number in week 8 but increased 10 times by the $10^{\text {th }}$ week. Conversely cv. MI7 had among the highest copy number in $8^{\text {th }}$ week, but was among the lowest two weeks later.

\section{Discussion}

The OYVMD caused by BYVMV and associated betasatellite has been responsible for significant economic loss in okra production in recent years in Sri Lanka (Jeyaseelan et al., 2018; Senevirathna et al., 2016). Effective management of the disease requires intensive efforts in breeding for resistance. Both symptoms and transmission potential need to be 
reduced, since symptomless but high titre varieties are a hazard for other crops. The primary limitation in screening resistance varieties is rapid quantification of disease-causing agents. In this study, a protocol for absolute quantification of BYVMBs was developed in order to make virus resistance assessments quicker and more informative.

Few attempts have been made in the past to find okra varieties resistant to OYVMD. In these studies screening was mainly based on visual symptoms (Ahmed and Patil, 2004; Benchasri, 2012; Kumar and Raju, 2017; Kumar and Reddy, 2015; Vijaya and Joshi, 2013) with a few studies using serological tests (Asare-bediako et al., 2017). More than 50 improved varieties and hybrids have been released in India but resistance to begomoviruses is found to be unstable, with frequent breakdowns. This may be due to pathogenic variability or to selection of okra lines which are symptomless carriers (Mishra et al., 2017). Although Venkataravanappa et al. (2013) have shown the use of non-radioactive DNA probes for the routine large-scale diagnosis of geminiviruses affecting okra, more sensitive cost-effective and user-friendly DNA-based diagnostics are needed for large-scale screening of germplasm for viral disease resistance.

Two main qPCR based quantification techniques, relative and absolute, have emerged from studies on virus detection. Absolute quantification with a known standard is the most commonly used for plant virus quantification (Herrera-vásquez et al., 2015; Rao and Sun, 2015; Shafiq et al., 2017). On the other hand, relative quantification uses a comparative quantification with internal reference endogenous housekeeping control genes (Bester et al., 2014; Kundu, 2012; Liu et al., 2013). Absolute quantification used in present study has several advantages: there is no need to use reference genes which can be difficult to select (Kundu, 2012) and whose expression may vary among tissues/organs and may change due to environmental conditions; the method focuses entirely on the betasatellite and avoids the influence of other factors; protocols are much easier to optimize and scale out to other patho- 
systems; and finally, standard templates are preserved in plasmids where they are stable and can be stored for long periods (Shirima et al., 2017).

The use of appropriate standard templates in generating standard curves is an important requirement for obtaining accurate absolute quantification data. Cloned DNA is very stable and therefore gives reliable results as it generates highly reproducible standard curves (Shirima et al., 2017). In present study standard serial dilution curve was obtained with acceptable qPCR efficiency for BYVMB (95.1\%). The efficiency proved the balance among enzyme, dNTPs, primers and templates. The linearity of the relation between copy number and $\mathrm{Ct}$ was excellent, with $\mathrm{R}^{2}$ of 0.996 . We therefore suggest that this qPCR protocol could be used to detect quantitatively BYVMB in routine virus diagnosis.

In this study, absolute quantification was done using SYBR Green I chemistry. This is desirable because the assay is simpler and cheaper than probe-based assays such as TaqMan. Methods based on SYBR Green can have drawbacks due to binding to primer dimers and non-specific PCR products. Subsequent melting curve analysis of PCR products can be used to confirm the specificity of PCR amplification. In present study, melting curve analysis showed a single peak in all PCR products, including samples from multiple varieties, tissues and plant maturities. This confirms the specificity of the primers and reliability of the protocol.

Examination of large numbers of samples and genotypes collected from diverse environments is necessary in order to draw appropriate conclusions during selection of resistant varieties (Shirima et al., 2017), especially for selection based on visual symptoms. The samples used in this study were from different varieties grown in single location as well as samples collected from diverse environments, but with a moderate number of samples. The qPCR 
based assay used in this study was highly sensitive and can quantitate even symptomless infections, so assays can be done with few replicates.

DNA extracted from healthy okra plant grown in insect proof cage was used as negative control and gave negative results for all the three methods. However, apparently healthy plants (severity scale 0) collected from infected field had positive betasatellite titres. The plants had about 1000 BYVMBs in 1ng/ $\mu$ l total DNA, but there were no symptoms and endpoint PCR were not able to detect them. At the same time, samples of severity scale 1 had $1 \times 10^{6}$ number of virus particles and all three methods were able to detect it. This makes two points clear. First, the qPCR method is more sensitive than the methods currently available to detect BYVMBs in okra. Second, to produce visible symptoms BYVMBs must exceed a threshold concentration. The threshold may be determined by the amount of helper begomovirus and/or by defence mechanisms of the okra, and may therefore vary with environment and plant history. Above that threshold level, the severity of the disease increases linearly with copy number of BYVMBs per unit of DNA extracted.

In the field, betasatellites are transmitted with their helper virus from one plant to another by whiteflies. A whitefly which feed on symptomless infected plant may transmit the betasatellite and helper virus to healthy plants in the same field or nearby fields before development of visible symptoms. Presence of BYVMB in symptomless plants is highly favour for wide spread of disease in short period of time. Therefore, it is necessary to consider preventive disease management practices rather than implementing control measures after development of visible symptoms in okra cultivation.

In conclusion, the present study shows that qPCR is a useful method to detect and quantify BYVMBs in okra. It is especially valuable for plant samples with betasatellite titre lower than the detection limit of conventional methods. This method should be of utility to all those 
aiming to study the behaviour of BYVMB in okra plants and to select for improved resistance to these economically damaging viruses.

\section{Acknowledgements}

The authors are grateful to Dr. George Gibbings and Dr. Ihsan Ullah (Molecular Genetics Laboratory, School of Agriculture, Policy and Development, University of Reading, UK) for technical assistance.

\section{References}

Ahmed, Z., Patil, M., 2004. Screening of okra varieties against okra yellow vein mosaic virus. Karnataka J. Agric. Sci. 17, 613-614.

Ammara, U., Al-sadi, A.M., Al-shihi, A., Amin, I., 2017. Real-time qPCR assay for the TYLCV titer in relation to symptoms- based disease severity scales. Int. J. Agric. Biol. 19, 145-151. https://doi.org/10.17957/IJAB/15.0256

Asare-bediako, E., Agyarko, F., Verbeek, M., Taah, K.J., Asare, A., Agyei, F.K., Sarfo, J., Eghan, M.J., Combey, R., 2017. Variation in the susceptibility of okra ( Abelmoschus esculentus L. Moench ) genotypes to okra mosaic virus and Podagrica species under field conditions. J. Plant Breed. Crop Sci. 9, 79-89. https://doi.org/10.5897/JPBCS2017.0650

Benchasri, S., 2012. Screening for yellow vein mosaic virus resistance and yield loss of okra under field conditions in Southern Thailand. J. Anim. Plant Sci. 12, 1676-1686.

Bester, R., Pepler, P.T., Burger, J.T., Maree, H.J., 2014. Relative quantitation goes viral : An RT-qPCR assay for a grapevine virus. J. Virol. Methods 210, 67-75. 
Bhattacharyya, D., Gnanasekaran, P., Kumar, R.K., Kushwaha, N.K., 2015. A geminivirus betasatellite damages the structural and functional integrity of chloroplasts leading to symptom formation and inhibition of photosynthesis. J. Exp. Bot. 66, 5881-5895. https://doi.org/10.1093/jxb/erv299

Briddon, R.W., Brown, J., Moriones, E., Stanely, J., Zerbini, M., Zhou, X., Fauquet, C.M., 2008. Recommendations for the classification and nomenclature of the DNA- beta satellites of begomoviruses. Arch. Virol. 153, 763-781. https://doi.org/10.1007/s00705007-0013-6

Briddon, R.W., Bull, S.E., Mansoor, S., Amin, I., Markham, P.G., 2002. Universal primers for the PCR-mediated amplification of DNA $\beta$. Mol. Biotechnol. 20, 315-318.

Brown, J.K., Zerbini, M., Navaa-Castillo, J., Moriones, E., Ramos-Sobrinho, R., Silva, J., Fiallo-Olive, E., Briddon, R.W., Hernandez-Zepeda, C., Idris, A., Malathi, V., Martin, D.P., Rivera-Bustamante, R., Ueda, S., Varsani, A., 2015. Revision of Begomovirus taxonomy based on pairwise sequence comparisons. Arch. Virol. 160, 1593-1619. https://doi.org/10.1007/s00705-015-2398-y

Deng, D., Mcgrath, P., Robinson, D.J., Harrison, B.D., 1994. Detection and differentiation of whitefly-transmitted geminiviruses in plants and vector insects by the polymerase chain reaction with degenerate primers. Ann. Appl. Biol. 125, 327-336.

Ghosh, R., Paul, S., Ghosh, S.K., Roy, A., 2009. An improved method of DNA isolation suitable for PCR-based detection of begomoviruses from jute and other mucilaginous plants. J. Virol. Methods 159, 34-39. https://doi.org/10.1016/j.jviromet.2009.02.020

Herrera-vásquez, J.A., Rubio, L., Alfaro-fernández, A., Elvira, D., Font-san-ambrosio, I., Falk, B.W., Ferriol, I., 2015. Detection and absolute quantitation of Tomato torrado virus (ToTV) by real time RT-PCR. J. Virol. Methods 221, 90-94. 
Jeyaseelan, T.C., Jeyaseelan, E.C., Costa, D.M. De, Shaw, M.W., 2018. Molecular characterization and phylogenetic analysis of betasatellite molecules associated with okra yellow vein mosaic disease in Sri Lanka. Trop. Plant Pathol. 43, 468-472. https://doi.org/10.1007/s40858-018-0225-1

Jose, J., Usha, R., 2003. Bhendi yellow vein mosaic disease in India is caused by association of a DNA betasatellite with a begomovirus. Virology 305, 310-317. https://doi.org/10.1006/viro.2002.1768

Kumar, G.S., Raju, S.V.S., 2017. Screening of certain okra genotypes against yellow vein mosaic virus disease under field conditions. Int. J. Curr. Microbiol. Appl. Sci. 6, 14611466.

Kumar, S., Reddy, M.T., 2015. Morphological characterization and agronomic evaluation of yellow vein mosaic virus resistant single cross hybrids for yield and quality traits in okra ( Abelmoschus esculentus L . Moench ). Open Access Libr. J. 2. https://doi.org/10.4236/oalib.1101720

Kundu, J., 2012. Evaluation of reference genes for the relative quantification of apple stem grooving virus and apple mosaic virus in apple trees. Indian J. Virol. 23, 39-41. https://doi.org/10.1007/s13337-012-0065-4

Liu, W., Zhao, X., Zhang, P., Mar, T.T., Liu, Y., Zhang, Z., Han, C., Wang, X., 2013. A one step real-time RT-PCR assay for the quantitation of Wheat yellow mosaic virus ( WYMV ). Virol. J. 10:173.

Mishra, G.P., Singh, B., Seth, T., Singh, A.K., Halder, J., 2017. Biotechnological advancements and begomovirus management in okra ( Abelmoschus esculentus L .): status and perspectives. Front. Plant Sci. 8, 1-16. https://doi.org/10.3389/fpls.2017.00360 
Ndunguru, J., Rajabu, A.C., 2004. Effect of okra mosaic virus disease on the above-ground morphological yield components of okra in Tanzania. Sci. Hortic. (Amsterdam). 99, 225-235. https://doi.org/10.1016/S0304-4238(03)00108-0

Rao, X., Sun, J., 2015. Development of SYBR Green I based Real-Time RT-PCR assay for specific detection of watermelon silver mottle virus. Iran. J. Biotechnol. 13, 20-24. https://doi.org/10.15171/ijb.1124

Senevirathna, H.M.S.I., Wasala, S.K., Senanayake, D.M.J.B., Weerasekara, D., Wickamasinghe, H.A.M., Deepal, P.K.G., 2016. Characterization and detection of yellow vein disease of okra ( Abelmoschus esculentus ( L .) Moench ) in Sri Lanka. Trop. Agric. Res. 27, 360-369.

Sergius, U.O., Esther, D.U., 2014. Screening of Abelmoschus esculentus and Abelmoschus callei cultivars for resistance against okra leaf curl and okra mosaic viral diseases, under field conditions in South Eastern Nigeria. African J. Biotechnol. 13, 4419-4429. https://doi.org/10.5897/A

Shafiq, A.M., Iqbal, Z., Ali, I., 2017. Real-time quantitative PCR assay for the quantification of virus and satellites causing leaf curl disease in cotton in Pakistan. J. Virol. Methods. 248, 54-60. https://doi.org/10.1016/j.jviromet.2017.05.012

Shirima, R.R., Maeda, D.G., Kanju, E., Ceasar, G., Tibazarwa, F.I., Legg, J.P., 2017. Absolute quantification of cassava brown streak virus mRNA by real-time qPCR. J. Virol. Methods 245, 5-13. https://doi.org/10.1016/j.jviromet.2017.03.003

Venkataravanappa, V., Reddy, C.N.L., Reddy, M.K., 2013. Begomovirus characterization, and development of phenotypic and DNA-based diagnostics for screening of okra genotype resistance against Bhendi yellow vein mosaic virus. 3 Biotech 3, 461-470. https://doi.org/10.1007/s13205-012-0107-z 
Vijaya, M., Joshi, V., 2013. Screening for yellow vein mosaic virus resistance of okra under Hyderabad conditions. Asian J. Hortic. 8, 763-766. 
Table 1: Details of betasatellite nucleotide sequences retrieved from GenBank to design qPCR primers.

\begin{tabular}{|c|c|c|c|}
\hline Beta-satellites & Accession No & Abbreviation & Size (bp) \\
\hline Okra yellow vein mosaic betsatellite [India:Maharashtra:Aurangabad:2008] & GU233520 & OYVMB[IN:Aur:08] & 1358 \\
\hline Bhendi yellow vein mosaic betasatellite [India:Madurai:Muthuppatti:2001] & AJ308425 & BYVMB[IN:Mad:01] & 1353 \\
\hline Bhendi yellow vein betasatellite [India:Varanasi:2008] & HM590506 & BYVB[IN:Var:08] & 1360 \\
\hline Bhendi yellow vein mosaic betasatellite [India:Guntur:OY112:2006] & GU111969 & BYVMB[IN:Gun:OY112:06] & 1356 \\
\hline Bhendi yellow vein mosaic betasatellite [India:Madurai:MKU-1:2014] & KR068483 & BYVMB[IN:Mad:MKU-1:14] & 1342 \\
\hline Bhendi yellow vein mosaic betasatellite [India:Barrackpore:2007] & EF417919 & BYVMB[IN:Bar:07] & 1354 \\
\hline Bhendi yellow vein betasatellite [India:Coimbatore:Co:2009] & KJ462077 & BYVB[IN:Coi:Co:09] & 1351 \\
\hline Bhendi yellow vein betasatellite [India:Dhanbad:2008] & HM590504 & BYVB[IN:Dha:08] & 1351 \\
\hline Bhendi yellow vein mosaic betasatellite [Sri Lanka: Vavuniya: 2015] & KX174318 & OYVMB [LK:Vav:15] & 1318 \\
\hline Bhendi yellow vein mosaic betasatellite [Sri Lanka: Jaffna: 2015] & KX174319 & OYVMB [LK:Jaf:15] & 1334 \\
\hline Bhendi yellow vein mosaic betasatellite [Sri Lanka: Kandy: 2015] & KX174320 & OYVMB [LK:Kan:15] & 1369 \\
\hline Bhendi yellow vein mosaic betasatellite [Sri Lanka: Trincomalee: 2015] & KX174322 & OYVMVB [LK:Tri:15] & 1320 \\
\hline Bhendi yellow vein mosaic betasatellite [Sri Lanka: Puttalam: 2015] & KX174323 & OYVMVB [LK:Put:15] & 1351 \\
\hline Bhendi yellow vein betasatellite [India:CN4B:2015] & KU500808 & BYVB[IN:CN4B:15] & 1200 \\
\hline Bhendi yellow vein mosaic betasatellite [India:Pandarahalli:OY174:2006] & GU111972 & BYVMB[IN:Pan:OY174:06] & 1352 \\
\hline
\end{tabular}


Fig. 1. Different severity levels of OYVMD. (a) Both scale 0 (no visible symptoms) and 1 (very mild symptoms with initial vein clearing in young leaves); (b) Scale 2 (veins completely yellow and interveinal regions remain green); (c) Scale 3 (whole leaf yellow in colour); Scale 4 (yellowish and deformed pods with whole leaf yellow coloured).

Fig. 2. End point PCR products of partial DNA-A sequence of BYVMV. $20 \mathrm{ng}$ of DNA samples of okra leaves with different severity scales were amplified using primers targeting a segment of gene coding for capsid protein (Deng et al. 1994). The product length was about 550 base. Lane 1- severity scale 0; lane 2 - severity scale 1; lane 3 - DNA marker (100 bp opti-DNA markers, Applied Biological Materials Inc.); lane 4 - severity scale 2; lane 5 severity scale 3 ; lane 6 - severity scale 4 .

Fig. 3. End point PCR products of complete BYVMB. $20 \mathrm{ng}$ of DNA samples of fieldsampled okra leaves with different severity scales were amplified using primers specific to BYVMBs (Briddon et al., 2002). DNA size marker was HyperLadder 1 (BIOLINE).

Fig. 4. Multiple sequence alignment of a portion (from 211 bp to $316 \mathrm{bp}$ ) of $\beta C 1$ gene of different beta-satellites associated with Okra yellow vein mosaic disease. It shows conservation of primers designed for detection in the qPCR.

Fig. 5. (a) Standard curve obtained for tenfold serial dilution of cloned plasmids. The curve was drawn Ct against different concentrations of cloned plasmids. (b) Melting curves for the 
qPCR products. The primer pairs qbetaF3 and qbetaR3 amplified a 106 base segment of $\beta C 1$ gene in BYVMB. The melting curve analysis of the qPCR product showed a single peak at $76.62{ }^{\circ} \mathrm{C}$.

Fig. 6. Copy number of BYVMBs in okra leaf samples with different severity scores. Three replicate leaves at each severity level were measured (see Figure 1). The coefficient of variation of a mean is approximately 9\%. The confidence limits for scale 0 are 1192-1474.

Fig. 7. Box-plot of measured copy number of BYVMBs in three different tissues of young and mature symptomatic okra leaves. Young and mature leaves were collected from six different plants and in each leaf BYVMB titre was quantified in lamina, petiole and mid-rib (S.E.M for factorial ANOVA, based on biological replicate differences $=134000$ ).

Fig. 8. Copy number of BYVMBs in different okra varieties at two different time points. Eight different okra varieties were cultivated in a single field and natural infestation by whiteflies allowed. BYVMBs were quantified in three biological replicates of each variety; error bars are 1 SEM based on variation between biological replicates, from ANOVA. The variety Maha-F1 samples did not have detectable BYVMB. 